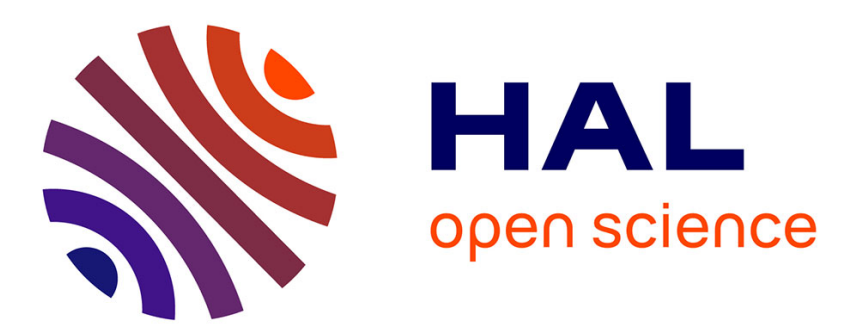

\title{
The role of mechanical stimuli in the vascular differentiation of mesenchymal stem cells
} Pan Dan, Emilie Velot, Véronique Decot, Patrick Menu

\section{To cite this version:}

Pan Dan, Emilie Velot, Véronique Decot, Patrick Menu. The role of mechanical stimuli in the vascular differentiation of mesenchymal stem cells. Journal of Cell Science, 2015, 128 (14), pp.2415-2422. $10.1242 /$ jcs.167783 . hal-01465904

\section{HAL Id: hal-01465904 \\ https://hal.univ-lorraine.fr/hal-01465904}

Submitted on 13 Feb 2017

HAL is a multi-disciplinary open access archive for the deposit and dissemination of scientific research documents, whether they are published or not. The documents may come from teaching and research institutions in France or abroad, or from public or private research centers.
L'archive ouverte pluridisciplinaire HAL, est destinée au dépôt et à la diffusion de documents scientifiques de niveau recherche, publiés ou non, émanant des établissements d'enseignement et de recherche français ou étrangers, des laboratoires publics ou privés. 


\title{
The role of mechanical stimuli in the vascular differentiation of mesenchymal stem cells
}

\author{
Pan Dan ${ }^{1,2}$, Émilie Velot ${ }^{1}$, Véronique Decot ${ }^{1,3}$ and Patrick Menu ${ }^{1, *}$
}

\begin{abstract}
Mesenchymal stem cells (MSCs) are among the most promising and suitable stem cell types for vascular tissue engineering. Substantial effort has been made to differentiate MSCs towards vascular cell phenotypes, including endothelial cells and smooth muscle cells (SMCs). The microenvironment of vascular cells not only contains biochemical factors that influence differentiation, but also exerts hemodynamic forces, such as shear stress and cyclic strain. Recent evidence has shown that these forces can influence the differentiation of MSCs into endothelial cells or SMCs. In this Commentary, we present the main findings in the area with the aim of summarizing the mechanisms by which shear stress and cyclic strain induce MSC differentiation. We will also discuss the interactions between these mechanical cues and other components of the microenvironment, and highlight how these insights could be used to maintain differentiation.
\end{abstract}

KEY WORDS: Mesenchymal stem cells, Differentiation, Shear stress, Cyclic strain, Vascular tissue engineering

\section{Introduction}

Cardiovascular diseases, particularly clogging of the coronary artery, remain the biggest cause of mortality worldwide. Coronary artery bypass grafts (CABGs) are considered gold standard procedures for these diseases. Although the left internal mammary arteries and saphenous veins are still the preferential sources for CABGs, vascular tissue engineering has proven to be an attractive alternative. The engineering of small-diameter $(<6 \mathrm{~mm})$ vascular tissue has greatly advanced over the past two decades, with the majority of research efforts having been aimed at the generation of vascular grafts that mimic blood vessels.

Blood vessels typically comprise three main layers - the intima layer, which comprises endothelial cells; the media layer, which comprises smooth muscle cells (SMCs); and the outermost layer (adventitia), which is made up of fibroblasts and extracellular matrix (ECM) components. Endothelial cells are usually characterized by the expression of VE-cadherin, CD31 (also known as PECAM1) and vascular endothelial growth factor receptor 2 (VEGFR2, encoded by $K D R$ ), and by their capacity to take up acetylated low-density lipoproteins (ac-LDL), to form tubes in Matrigel ${ }^{\circledR}$ and to release nitric oxide. Smooth muscle cells, by contrast, are typified by the expression of contractile markers, such as smooth muscle $\alpha$-actin (SMA, also known as ACTA2), calponin 1, SM22 $\alpha$ (also known as

${ }^{1}$ UMR 7365 CNRS Université de Lorraine, Ingenierie Moleculaire et Physiopathologie Articulaire, Department of Cell and Tissue Engineering, Vectorization, Imaging, Biopôle de l'Université de Lorraine, Avenue de la forêt de Haye, C.S. 50184, Vandœuvre-lès-Nancy Cedex F-54505, France. ${ }^{2}$ Department of Thoracic and Cardiovascular surgery, Zhongnan hospital of Wuhan University, Wuhan, 430071, China. ${ }^{3} \mathrm{CHU}$ de Nancy, Unité de Thérapie Cellulaire et Tissus, allée du Morvan, Vandœuvre-lès-Nancy F-54500, France.

*Author for correspondence (patrick.menu@univ-lorraine.fr)
TAGLN) and smooth muscle myosin heavy chain (SMMHC, also known as MYH11), and by the ability to synthesize ECM proteins (Owens, 1995). To be viable, the constructed graft needs to exhibit at least the following four properties - (i) a burst pressure superior to that of the saphenous veins; (ii) a long-term potency that resists the pressure of physiological circulation; (iii) avoidance of platelet adhesion that induces clot formation; and (iv) ease of engineering (L'Heureux et al., 2007). The first tissue-engineered blood vessel with these properties was constructed in 1998 and contained SMCs and endothelial cells that had both been isolated from human umbilical veins (L'Heureux et al., 1998). However, the use of mature vascular cells (i.e. those isolated from native blood vessels) is inherently limited because acquiring them demands an invasive procedure, they are typically available in insufficient quantities and they exhibit a low rate of proliferation (Shin'oka et al., 2001; Koike et al., 2004; L'Heureux et al., 2006). Thus, in order to advance vascular tissue engineering, stem cells have been intensively explored as alternative sources for both mature endothelial cells and SMCs (Ferreira et al., 2007). Among the various stem cell types that are suitable for application in vascular grafts, mesenchymal stem cells (MSCs) have been most extensively studied to date (Seifu et al., 2013). MSCs are found in different types of tissue of adult or perinatal origin, such as bone marrow, adipose tissue or Wharton's jelly from the umbilical cord (El Omar et al., 2014). Their high proliferation rate, multipotency and immunomodulatory properties make them a highly suitable candidate for vascular tissue engineering.

A number of factors are typically required to initiate vascular differentiation of stem cells in vitro. VEGF proteins are commonly used for differentiation into endothelial cells (Oswald et al., 2004), and transforming growth factor $\beta 1$ (TGF- $\beta 1$ ) or platelet-derived growth factor (PDGF) for differentiation into SMCs. In addition to these biochemical factors, the microenvironment of vascular cells exerts two main hemodynamic forces, shear stress and cyclic strain, which contribute to the differentiation process. Shear stress is generated by the blood passing through vessels, whereas cyclic strain is created by the pulsatile nature of blood flow, which produces a tensile stress that acts perpendicular to the vessel wall (Fig. 1). In vitro, both of these two mechanical cues can be replicated by different models, such as using a parallel-plate chamber for shear stress and a longitudinal stretch system for cyclic strain (see Box 1). MSCs are highly responsive to their mechanical environment, and different types of forces applied to the same MSC population result in divergent outcomes (Maul et al., 2011). Therefore, in this Commentary, we will summarize the available literature that describes a role for mechanical forces in the differentiation of MSCs into vascular cells and discuss different means to maintain differentiation.

\section{The role of shear stress in the endothelial differentiation of MSCs}

Endothelial cells regulate vascular tone and mural remodelling in a shear-dependent manner, which is commonly assumed to maintain 


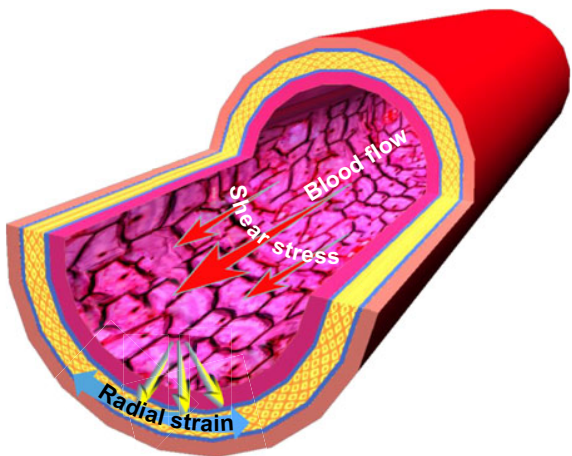

Fig. 1. Mechanical forces in native blood vessels. Endothelial cells are exposed to shear stress that is generated by blood flowing across the lumen surface. Because of the pulsatile nature of the hemodynamic stream, both endothelial cells and SMCs experience a cyclic tensile strain that is perpendicular to the vessel wall.

a constant level of wall shear stress across arteries. Recently published data suggest that the flow velocity experienced by endothelial cells varies in a species-dependent manner (Weinberg and Ross Ethier, 2007). In this section, we will summarize the main results published to date pertaining to the possibility of using mechanical stimulation to induce the differentiation of human and animal cells into endothelial cells.

\section{The effect of shear stress on endothelial cells and MSCs}

As pointed out earlier, the endothelium is in direct contact with blood and is therefore exposed to shear stress, which is in turn required for the development of new blood vessels both in embryos and in adults (le Noble et al., 2004; Folkman and Haudenschild,

\section{Box 1. In vitro models of shear stress and cyclic strain for} the differentiation of MSCs

The endothelium is exposed to both laminar and pulsatile shear stresses in blood vessels. In order to mimic the effect of flow on cultured MSCs, various types of device are typically used, including parallel-plate chambers, orbital shakers, and tubular and microfluidic devices. Parallel-plate chambers are constructed by sandwiching a silicone gasket between the plate chamber and a glass slide that is seeded with cells. A peristaltic pump then drives the medium through the chamber in order to generate a 2D laminar shear stress on the cells (Wang et al., 2005; Wu et al., 2008; Bai et al., 2010; Maul et al., 2011). Orbital shakers (or rotating disks) rotate the medium-coated disk so that the medium flows concentrically, thus generating laminar or turbulent shear stress over cells that are seeded onto the bottom of the disk (Fischer et al., 2009; Zhang et al., 2009; Bassaneze et al., 2010). Tubular shear stress systems perfuse medium through a tubular scaffold, the inner layer of which is seeded with MSCs (Kim et al., 2011; Dong et al., 2009; O'Cearbhaill et al., 2008). Microfluidic systems contain submillimeter-sized modules that are made out of gel, such as collagen, and filled with the cells of choice; these modules are then packed into a chamber with pillars to hold them in place, before the chamber is connected to a flow circuit to undergo fluid perfusion (Bruzewicz et al., 2008; Khan and Sefton, 2010; Khan et al., 2012).

To stretch MSCs, cells are usually seeded onto a flexible silicone membrane, which is elongated by negative suction to generate an equixial cyclic strain (Park et al., 2004; Gong and Niklason, 2008). Uniaxial cyclic strain can be generated by connecting one end of a membrane to a fixed frame while the other end is attached to a movable frame, thus producing a one-way motion (Park et al., 2004; Jang et al., 2011). Many of the bioreactors available today generate cyclic circumferential stretch together with axial stretch (reviewed by Huang and Niklason, 2014). (For more information, see Zhou and Niklason, 2012; Mironov et al., 2011).
1980). Blood flow in small-diameter arteries generates shear stresses that are within the range of $10-20 \mathrm{dyn} / \mathrm{cm}^{2}$ in humans (Giddens et al., 1993). Such hemodynamic shear stress on endothelial cells is in fact important for the maintenance of the phenotype, orientation, metabolic activities and homeostasis of the vascular endothelium (Davies, 2009). Furthermore, blood flow exerts an anti-thrombotic effect in vessels by inducing the release of thrombomodulin by endothelial cells, which inactivates the procoagulant factor thrombin and activates the anticoagulant protein $\mathrm{C}$ (Yamawaki et al., 2005). As endothelial cells are an essential component of the vessel wall, much of the research has focused on obtaining endothelial cells in vitro after stem cell differentiation. Given the crucial role of shear stress in the differentiation of endothelial cells in vivo, it is believed that replicating shear stress in cell culture (in vitro) could be crucial for differentiating the stem cells towards the endothelial phenotype (Ahsan and Nerem, 2010; Yamamoto et al., 2005; Cheng et al., 2013).

The effect of shear stress on different types of MSCs has been studied previously. For example, bone-marrow-derived MSCs from a number of species are able to differentiate into endothelial-like cells when they are stimulated through physiological shear stress conditions (Engelmayr et al., 2006; Bai et al., 2010; Huang et al., 2010; Maul et al., 2011; Dong et al., 2009; Kim et al., 2011). Likewise, MSCs derived from human adipose tissue (hASCs) (Bassaneze et al., 2010; Zhang et al., 2011; Shojaei et al., 2013) and MSCs from other sources, such as amniotic fluid cells (Zhang et al., 2009) and human placenta (Wu et al., 2008), have also been shown to differentiate into endothelial-like cells under shear stress (see Table 1 for a summary).

\section{Is shear stress sufficient for differentiation of MSCs?}

In addition to shear stress, the physiological microenvironment of the vessels also plays a role in endothelial cell differentiation, particularly if it contains VEGF proteins. This effect has been shown in a study that compared the consequences of shear stress, treatment with VEGF-family members or a combination of both stimuli on rat MSCs (Bai et al., 2010). In that report, the two stimuli are shown to have a synergistic effect on endothelial cell differentiation. Furthermore, when VEGF was removed from the culture, and shear stress was continued for up to $48 \mathrm{~h}$, loss of endothelial markers was observed, suggesting that de-differentiation had begun. By contrast, another study did not observe any endothelial cell markers on hASCs that had been treated with $10 \mathrm{dyn} / \mathrm{cm}^{2}$ of shear stress alone, even after $96 \mathrm{~h}$ of stimulation (Bassaneze et al., 2010). The authors suggest that the failure to differentiate is caused by the lack of VEGFR2 expression in hASCs, which is essential to induce their differentiation into endothelial cells (Bassaneze et al., 2010).

A synergy between VEGF proteins and shear stress had already been shown in two studies (Wu et al., 2008; Fischer et al., 2009). When cells were cultured in endothelial cell growth supplement for 3 days under static conditions and subsequently exposed to shear stress of $12 \mathrm{dyn} / \mathrm{cm}^{2}$ for at least $24 \mathrm{~h}$, expression of CD31 and increased ac-LDL uptake were observed, as well as tube formation in vitro. Analogous results have been obtained by Zhang et al., who report that MSCs derived from human amniotic fluid and hASCs that have been cultivated in endothelial cell differentiation medium EGM $^{\mathrm{TM}}-2$ for two weeks express von Willebrand factor (vWF) and CD31, and gain the ability to release endothelial nitric oxide synthase (eNOS, also known as NOS3) and to form tubes on Matrigel ${ }^{\circledR}$. The subsequent application of shear stress further increases the expression of endothelial markers and enhanced functional characteristics (Zhang et al., 2009). 
Table 1. Summary of the effects of shear stress on endothelial differentiation of MSCs

\begin{tabular}{|c|c|c|c|c|}
\hline $\begin{array}{l}\text { Mechanical force } \\
\text { regime }\end{array}$ & Stem cell type & Stimulation & $\begin{array}{l}\text { Effect of mechanical stimuli on the } \\
\text { differentiation outcome }\end{array}$ & References \\
\hline $\begin{array}{l}\text { Shear stress alone } \\
\text { on cells of animal } \\
\text { origin }\end{array}$ & $\begin{array}{l}\text { Murine MSC line } \\
\text { C3H10T1/2 } \\
\text { Canine BMMSCs }\end{array}$ & $\begin{array}{l}\text { Pulsatile shear stress for } 6 \text {, } \\
12 \text { and } 24 \mathrm{~h} \\
\text { 3D pulsatile shear stress of } \\
15 \text { dyn } / \mathrm{cm}^{2} \text { for } 4 \text { days }\end{array}$ & $\begin{array}{l}\text { Expression of endothelial cell markers, cell } \\
\text { alignment, inhibition of SMC marker TGF- } \beta \\
\text { Cell alignment, upregulation of endothelial cell } \\
\text { markers and downregulation of SMC } \\
\text { markers }\end{array}$ & $\begin{array}{l}\text { Wang et al., } \\
2005,2008 \\
\text { Dong et al., } \\
2009\end{array}$ \\
\hline
\end{tabular}

Rat BMMSCs Pre-treatment with VEGF for 7 days, shear stress with or without pretreatment

Rat BMMSCs

Laminar shear stress of 1 or $20 \mathrm{dyn} / \mathrm{cm}^{2}$ up to 5 days

Shear stress alone on human MSCs

\section{shear stress and growth factors}

Combination of

shear stress and cyclic strain
Human ASCs
Human amniotic fluid derived MSCs/human ASCs

Human BMMSCs

Sheep BMMSCs

\begin{abstract}
Human ASCs
\end{abstract}
Human BMMSCs

Human placenta derived MSCs

Human BMMSCs

Human ASCs
Shear stress of $10 \mathrm{dyn} / \mathrm{cm}^{2}$ up to $96 \mathrm{~h}$

Shear stress of 2 or $20 \mathrm{dyn} / \mathrm{cm}^{2}$ for 2 days and subsequent static culture for 5 days

Cells cultured in $\mathrm{EGM}^{\mathrm{TM}}-2$ subsequently subjected to 6 or $12 \mathrm{dyn} / \mathrm{cm}^{2}$ shear stress

Pre-treatment with VEGF for 2 weeks and subsequent shear stress for 8 days

Pre-treatment with $\mathrm{EGM}^{\mathrm{TM}}$-2 medium for 2 weeks and shear stress for $48 \mathrm{~h}$

\section{Low (2.5 dyn $\left./ \mathrm{cm}^{2}\right)$ or high $\left(10 \mathrm{dyn} / \mathrm{cm}^{2}\right)$ shear stress took place in $\mathrm{EGM}^{\mathrm{TM}}-2$}

Cyclic flexure (1 Hz, 5\%) and shear stress (1.105 dyn $/ \mathrm{cm}^{2}$ ) for up to 3 weeks

Cyclic strain (1 Hz, 5\%) and shear stress (10 dyn $/ \mathrm{cm}^{2}$ ) for $24 \mathrm{~h}$

Combination of cyclic strain $(1 \mathrm{~Hz}, 10 \%)$, shear stress $\left(2.5 \mathrm{dyn} / \mathrm{cm}^{2}\right)$ and VEGF
Expression of endothelial cell markers under shear stress, which is enhanced by pretreatment; cell alignment is only observed under shear stress

Cell alignment and expression of endothelial cell markers under high shear stress, downregulation of endothelial cell markers under low shear stress, downregulation of SMC markers under both conditions

Failure to induce expression of any endothelial cell marker, no cell alignment, increased synthesis of nitric oxide

Endothelial cell differentiation owing to high levels of shear stress

Bai et al., 2010

Maul et al. 2011

Cell alignment owing to a combination of stimuli, more substantial expression of endothelial cell markers and endothelial cell functionality under high shear stress

Cell alignment, ac-LDL uptake and expression of CD31 2009

Endothelial cell differentiation during pretreatment, which was strengthened by shear stress application; shear-stressmediated endothelial cell differentiation that is dependent on PI3K but not on MAPKs

Low shear stress results in increased expression of endothelial cell markers, high shear stress leads to higher expression of SMC markers

Expression of endothelial cell markers when both stimuli are combined

Bassaneze et al., 2010

Yuan et al., 2013

Wu et al., 2008

Cell alignment and morphology similar to that of endothelial cells, but with considerable expression of SMC markers

Expression of endothelial cell markers
Zhang et al., 2009

Kim et al., 2011

Engelmayr et al., 2006

O'Cearbhaill et al., 2008

Shojaei et al., 2013

ac-LDL, acetylated low density lipoprotein; ASCs, adipose-derived MSCs; BMMSC, bone marrow mesenchymal stem cell; CD, cluster of differentiation; $\mathrm{EGM}^{\mathrm{TM}}$-2, endothelial growth medium; MAPK, mitogen-activated protein kinase; MSC, mesenchymal stem cell; PI3K, phosphatidylinositol 3-kinase; SMC, smooth muscle cell; TGF- $\beta$, transforming growth factor $\beta$; VEGF, vascular endothelial growth factor.

Taken together, these studies suggest that mechanical and biochemical influences synergize in order to increase endothelial cell functionality and the expression of endothelial cell markers.

\section{How does shear stress affect endothelial differentiation of MSCs?}

Inhibition of SMC differentiation

Although shear stress plays a role in endothelial cell differentiation, the underlying mechanism remains unclear. According to two independent studies, it appears that shear stress promotes endothelial differentiation, while downregulating differentiation towards a SMC phenotype (Wang et al., 2008; Dong et al., 2009). Specifically, the first study showed that murine MSCs subjected to a shear stress of $15 \mathrm{dyn} / \mathrm{cm}^{2}$ express VEGF, but significantly decrease their expression of other growth factors - such as TGF- $\beta 1$, as well as PDGF and its receptor - which are known to guide stem cells towards the SMC lineage (Wang et al., 2008). Similarly, Dong et al. have shown an increase in endothelial markers at both the mRNA and protein levels, whereas SMC markers, such as SMA and calponins, decrease after subjecting canine MSCs to a shear stress of $15 \mathrm{dyn}$ $\mathrm{cm}^{2}$ over 2 days (Dong et al., 2009). Furthermore, the effect of shear stress on differentiation has been shown to vary depending on stress 
intensity. For example, Kim et al. report that MSCs that have been exposed to low $\left(2.5 \mathrm{dyn} / \mathrm{cm}^{2}\right)$ or high $\left(10 \mathrm{dyn} / \mathrm{cm}^{2}\right)$ shear stress express endothelial markers, including CD31, vWF and VEGFR2. The expression of CD31 under low shear stress is considerably higher than that under high shear stress, whereas the expression of vWF and VEGFR2 is only slightly higher under low shear stress. Furthermore, MSCs that have been exposed to high shear stress show a significantly higher expression of SMC markers (myocardin, SMMHC and SM22 $\alpha$ ) (Kim et al., 2011). By contrast, other studies have suggested that shear stress increases the amount of TGF- $\beta 1$ and of SMC markers (Park et al., 2007; Kobayashi et al., 2004). These apparent inconsistencies regarding the expression of TGF- $\beta 1$ and SMC-specific markers could be attributable to the use of different types of stem cells, culture conditions or shear stress regimes.

\section{Effects on the balance between osteoblastic and endothelial differentiation}

The effects of mechanical forces on stem cell differentiation depends on the way the force is applied to cells (i.e. continuous stimulation or intermittent) and on its intensity; however, the fate of the stem cells might also be influenced by the stiffness of the substrate on which they are cultured. For example, two studies have reported that shear stress applied to stem cells leads to osteoblastic differentiation of MSCs (Lim et al., 2011; Yeatts et al., 2012). Furthermore, two studies by Kreke et al. have demonstrated that intermittent or low shear stress (below $3 \mathrm{dyn} / \mathrm{cm}^{2}$ ) induces osteocalcin expression by bone marrow MSCs that have been cultured on fibronectin and enhances the expression of other bone proteins compared with that of cells cultured with osteogenic factors under static conditions (Kreke et al., 2005, 2008). McBride et al. have followed a similar approach and investigated shear-stress-mediated gene expression changes in the MSC line $\mathrm{C} 3 \mathrm{H} / 10 \mathrm{~T} 1 / 2$ in order to determine the role of shear stress in osteogenesis (McBride et al., 2008). They find that exposure of cells to a continuous shear stress of either $0.2 \mathrm{dyn} / \mathrm{cm}^{2}$ or $1 \mathrm{dyn} / \mathrm{cm}^{2}$ for 30 or $60 \mathrm{~min}$ induces the upregulation of a number of ossification-related genes, including those encoding collagen type I, collagen type II, Runx2 and Sox9. In this experiment, the length of exposure to shear stress (30 or $60 \mathrm{~min}$ ) was a stronger predictor of the genes that are upregulated than the intensity of the applied shear stress. By contrast, in an earlier study that exposed the same cell line to laminar shear stress $\left(15 \mathrm{dyn} / \mathrm{cm}^{2}\right)$ for 6 or $12 \mathrm{~h}$, shear-stress-mediated upregulation of endothelial instead of bone differentiation markers was observed (Wang et al., 2005).

Taken together, these results indicate that the intensity and duration of the shear stress employed affects the balance between osteogenic and endothelial differentiation and could thus lead to different outcomes depending on the regime used.

\section{Effects of shear stress on mechanotransduction and associated signalling pathways}

On the basis that shear stress alone can direct differentiation towards an endothelial cell phenotype, the underlying molecular mechanism has been explored. Mechanosensitive cell surface molecules, such as primary cilia, integrins, ion channels and focal adhesion proteins, are able to mediate cellular responses to various forces. The primary cilium, which is ubiquitous in mammals, is an immotile microtubule-based organelle that protrudes from the apical surface and is able to bend in response to flow (Praetorius and Spring, 2005; Satir et al., 2010). A model for primary-cilia-based mechanosensing has been described in which bending of the cell cilium by shear flow can activate ion channels embedded in the membrane (Janmey and McCulloch, 2007). More recently, a study has provided evidence that primary cilia are involved in the osteogenic differentiation of human bone marrow MSCs (hBMMSCs) (Hoey et al., 2012). Other studies have suggested that transmembrane proteins, including ion channels and integrins, could be activated directly by shear flow as well as cyclic strain because these mechanical forces induce changes to the membranes - including altering membrane tension, which activates ion channel conductance (Liu and Lee, 2014). Opening of these channels increases the cytoplasmic concentration of the associated ion, which then changes the membrane potential, or, alternatively, the ions themselves can act as second messengers (Wu et al., 1999). For example, it has been shown that $\mathrm{Ca}^{2}$ ${ }^{+}$-signalling pathways can be activated through the activation of the mitogen-activated protein kinase (MAPK) pathway, which controls osteogenic differentiation of MSCs (Barradas et al., 2013).

Integrins not only bind to many components of the ECM, such as collagen and laminin, but also to other proteins, such as VEGF-A or insulin-like growth factor binding proteins (IGFBP1 and IGFBP2) (Vlahakis et al., 2007). Integrins link the ECM to the cytoskeleton and so facilitate the formation of focal adhesions between the cell and the ECM (Hoffman et al., 2011). At focal adhesions, integrins can also translate physical forces into biological signals (Schwartz and Assoian, 2001). Specific interactions formed by the $\alpha$ and $\beta$ subunits of integrins that are activated by shear stress trigger the focal adhesion kinase (FAK)-Src and the caveolin 1 (Cav1)-Fyn kinase pathways, thereby eliciting phosphorylation cascades of various downstream effectors and their interaction with each other through SH2- and SH3-domain-mediated interactions. The two pathways converge at the Raf-MEK-ERK axis in endothelial cells (Shyy and Chien, 2002). Cheng et al. have shown that the integrin-Ras-ERK pathway also has a role in endothelial cell differentiation. They report that exposure of endothelial progenitor cells (EPCs) to shear stress results in an increase in the endothelial maturation markers CD31 and vWF (Cheng et al., 2013). In this work, shear stress was also found to activate several mechanosensitive molecules, including integrin $\beta 1$, Ras, ERK1/2, paxillin and FAK, which are all involved in cytoskeletal rearrangements, as well as in the differentiation into late EPCs (Cheng et al., 2013).

Other cell surface molecules, such as G-protein-coupled receptors (GPCRs) and the glycocalyx, also serve as sensors of shear stress (Ando and Yamamoto, 2009; Stolberg and McCloskey, 2009). Mechanical stress and/or ligand binding induces conformational changes in the GPCRs, which transduce a signal to the cytoplasmic tail. Guanosine triphosphate (GTP) can provoke further conformational changes of the receptor, leading to its association with Ras, which in turn activates phosphoinositide 3-kinase (PI3K)-Akt pathway. This pathway has been shown to regulate MSC survival, proliferation, migration and other cellular fates through crosstalk with the Wntsignaling pathway (Huang et al., 2013). Furthermore, it has been shown that during endothelial cell differentiation of hASCs in response to shear stress, the acquisition of endothelial cell characteristics also depends on the PI3K-Akt pathway (Zhang et al., 2011). In this context, it is also worth mentioning that other protein kinases that are involved in cell growth and differentiation are recruited following mechanical stimulation of GPCRs, including p38-family MAPKs, ERK1/2, JNKfamily kinases and YAP/TAZ (Kaneko et al., 2014). Other pathways may be involved downstream of these surface molecules as recently reviewed in (Shah et al., 2014).

Role of cyclic strain in the differentiation of MSCs into SMCs SMCs are located in the middle layer of small-diameter arteries and play an important role in maintaining the elasticity and homeostasis of blood vessels. Their limited proliferative capacity and reduced 
collagen production thus prevent the formation of neointima (scar tissue) and luminal narrowing (Paszkowiak and Dardik, 2003).

Biochemical factors such as TGF- $\beta 1$ and PDGF have a wellestablished role in the differentiation of MSCs into SMCs. Successful SMC differentiation that is mediated by these growth factors is usually assessed by the expression of major SMC-specific proteins including SMA, SM22 $\alpha$, calponin-family proteins, heavy caldesmon (h-caldesmon) and SMMHC - contraction in response to carbachol and $\mathrm{KCl}$, and the production of ECM (Owens, 1995; Huang and Niklason, 2014). SMCs experience constant mechanical stimulation in blood vessels and undergo cyclic strain that results from pulsatile stresses from the systolic ejection of the heart. Under physiological conditions, the strain levels in blood vessels are in the range 5-30\% at frequencies of 30-90 cycles per minute $(0.5-1.5 \mathrm{~Hz})$ (Huang and $\mathrm{Li}, 2008)$. This phenomenon has generated interest in recent years, and a number of studies have investigated the effect of cyclic strain on MSC differentiation into SMCs (summarized in Table 2).

\section{Cyclic strain parameters for differentiation into SMCs}

Cyclic strain is usually generated in vitro by the repetitive extension and constriction of the elastic substrates onto which cells have been seeded. Cyclic strain can be applied and investigated in both twoand three-dimensional (2D and 3D, respectively) systems, with elastic silicone membranes most commonly used as a scaffold for 2D models and tubular matrices for 3D models. In 2D stretch models, cyclic strain is divided into uniaxial and equiaxial strains. Uniaxial strain refers to the fluid force along only one axis, whereas equiaxial strain describes uniform strain in all directions. Park et al. have compared the efficacies of equiaxial and uniaxial strain in inducing differentiation of hBMMSCs into SMCs in a 2D model. Equiaxial strain decreases the expression of the SMC markers SMA and SM22 $\alpha$, whereas uniaxial strain transiently increases their expression after 1 day of treatment. Furthermore, hBMMSCs align perpendicularly to the uniaxial strain axis but not that of the equiaxial strain (Park et al., 2004). In fact, the majority of studies using 2D models have been performed with uniaxial cyclic strain and result in SMC-like cells (Hamilton et al., 2004; Kurpinski et al., 2009; Jang et al., 2011; Ghazanfari et al., 2009). 3D models that are designed to replicate the status of SMCs in vivo because the radial distension of the tubular grafts that is induced by blood flow pressure allow cells to experience an effective uniaxial cyclic stain, similar to that in their natural environment (Du et al., 2011; Zheng et al., 2012). However, unlike the perpendicular orientation that is observed in most 2D uniaxial cyclic strain experiments, SMCs in native vessels align themselves parallel to the principal direction of the strain. Furthermore, comparison between the effects of 2D uniaxial strain and $3 \mathrm{D}$ radial distension on SMC differentiation has shown that the latter results in a significantly lower level of expression of

Table 2. Summary of the effects of cyclic strain on differentiation of MSCs into SMCs

\begin{tabular}{|c|c|c|c|c|}
\hline $\begin{array}{l}\text { Mechanical force } \\
\text { regime }\end{array}$ & Stem cell type & Stimulation & $\begin{array}{l}\text { Effect of mechanical stimuli on } \\
\text { the differentiation outcome }\end{array}$ & References \\
\hline \multirow[t]{5}{*}{ Cyclic strain alone } & Rat BMMSCs & $10 \%, 1 \mathrm{~Hz}$ uniaxial strain for 7 days & $\begin{array}{l}\text { Cell alignment perpendicular to cyclic strain, } \\
\text { expression of SMA and calponin }\end{array}$ & $\begin{array}{l}\text { Hamilton et al., } \\
2004\end{array}$ \\
\hline & Human BMMSCs & $\begin{array}{l}10 \%, 1 \mathrm{~Hz} \text { uniaxial and } \\
\text { equiaxial strain for } 1-3 \text { days }\end{array}$ & $\begin{array}{l}\text { Cell alignment perpendicular to cyclic strain and } \\
\text { transient increase of SMA, SM22 } \alpha \text { and collagen } \\
\text { type I only under uniaxial cyclic strain; equiaxial } \\
\text { strain results in downregulation of SMA and SM22 } \alpha\end{array}$ & Park et al., 2004 \\
\hline & Rat BMMSCs & $\begin{array}{l}10 \%, 1 \mathrm{~Hz} \text { longitudinal } \\
\text { strain for } 6 \text { days on } 3 \mathrm{D} \text { model }\end{array}$ & $\begin{array}{l}\text { Cell alignment parallel to cyclic strain, expression } \\
\text { of SMA and calponin, production of collagen }\end{array}$ & $\begin{array}{l}\text { Nieponice et al., } \\
2007\end{array}$ \\
\hline & Human BMMSCs & $\begin{array}{l}0-25 \%, 1-3 \mathrm{~Hz} \text { uniaxial strain } \\
\quad \text { for } 2-4 \mathrm{~h}\end{array}$ & $\begin{array}{l}\text { Cell alignment perpendicular to cyclic strain and SMA } \\
\text { expression }\end{array}$ & $\begin{array}{l}\text { Ghazanfari et al., } \\
2009\end{array}$ \\
\hline & Human BMMSCs & $\begin{array}{l}\text { 2D } 5 \%, 1 \mathrm{~Hz} \text { uniaxial } \\
\text { and } 3 \mathrm{D} \text { strain }\end{array}$ & $\begin{array}{l}\text { Greater increase in expression of SMA and calponin } \\
\text { proteins in } 2 D \text { compared with that in a } 3 D \text { model }\end{array}$ & $\begin{array}{l}\text { O’Cearbhaill } \\
\text { et al., } 2010\end{array}$ \\
\hline \multirow[t]{3}{*}{$\begin{array}{l}\text { Cyclic strain and } \\
\text { chemical factors }\end{array}$} & Murine MSC line & $\begin{array}{r}10 \%, 1 \mathrm{~Hz} \text { uniaxial strain } \\
\text { with TGF- } \beta 1 \text { for } 6 \text { days }\end{array}$ & $\begin{array}{l}\text { Cell alignment in the direction of cyclic strain, increase } \\
\text { in levels of SMA and SMMHC }\end{array}$ & Riha et al., 2007 \\
\hline & Human ASCs & $\begin{array}{r}10 \%, 1 \mathrm{~Hz} \text { uniaxial strain } \\
\text { with TGF- } \beta 1 \text { for } 7 \text { days }\end{array}$ & $\begin{array}{l}\text { Cell alignment in the direction of cyclic strain; cyclic } \\
\text { strain alone decreases the expression of SMC } \\
\text { markers, but combination of TGF- } \beta 1 \text { and cyclic } \\
\text { strain increases their levels }\end{array}$ & Lee et al., 2007 \\
\hline & Human ASCs & $\begin{array}{l}\text { TGF- } \beta 1 \text { and BMP- } 4 \text { for } 7 \text { days, } \\
\text { further cultivation on polyglycolic } \\
\text { acid for } 7 \text { days, then } 5 \% \text { strain for } \\
8 \text { weeks }\end{array}$ & $\begin{array}{l}\text { SMC differentiation is already induced by chemical } \\
\text { factors alone; cyclic strain further enhances the } \\
\text { expression of SMA and calponin, and the deposition } \\
\text { of collagen }\end{array}$ & $\begin{array}{l}\text { Wang et al., } \\
2010\end{array}$ \\
\hline \multirow[t]{2}{*}{$\begin{array}{l}\text { Cyclic strain and } \\
\text { use of parallel } \\
\text { microgrooves }\end{array}$} & Human BMMSCs & $\begin{array}{l}\text { Pre-treatment (or not) with TGF- } \beta 1 \\
\text { for } 24 \mathrm{~h} \text { and subsequent } 5 \%, 1 \mathrm{~Hz} \\
\text { uniaxial strain for } 24 \mathrm{~h} \text {, cells } \\
\text { cultivated in parallel groove }\end{array}$ & $\begin{array}{l}\text { Cell alignment parallel to the groove, expression of } \\
\text { calponin, perpendicular cyclic strain does not } \\
\text { change this alignment but reduces the levels of } \\
\text { calponins }\end{array}$ & $\begin{array}{l}\text { Kurpinski et al., } \\
\text { 2006, } 2009\end{array}$ \\
\hline & Rabbit MSCs & $\begin{array}{l}\text { Microgroove and } 3 \% \text { and } 10 \% \text {, } \\
0.26 \mathrm{~Hz} \text { uniaxial strain for } 3 \text { days }\end{array}$ & $\begin{array}{l}\text { Perpendicular cell arrangement on a flat surface with } \\
\text { grooves acting as obstacles for this orientation, } \\
\text { expression of SMA and h-caldesmon decreases } \\
\text { with } 3 \% \text { strain but increases with } 10 \% \text { strain, } \\
\text { maintenance of SMC marker expression on cells } \\
\text { grown on grooved surface after cyclic strain has } \\
\text { ceased }\end{array}$ & Jang et al., 2011 \\
\hline
\end{tabular}


SMC-associated markers (O'Cearbhaill et al., 2010). Although 2D uniaxial strain induces a different response from that of the in vivo situation in terms of cell alignment, it is nevertheless more effective in mediating differentiation than cyclic strain applied in a 3D model. It is thus clear that additional 3D models need to be developed which are able to better replicate in vivo conditions and thus might be more effective in directing differentiation towards SMCs (Smith and Gerecht, 2014).

In the case of rat and human MSCs, cyclic strain alone has been shown to induce the expression of some but not all SMC markers, in particular markers of mature SMCs such as SMMHC (Nieponice et al., 2007; Hamilton et al., 2004; Ghazanfari et al., 2009; O'Cearbhaill et al., 2010). In order to increase differentiation efficiency, cyclic strain can be applied in combination with other factors, such as growth factors. For instance, it has been shown that in order to maintain the SMC phenotype induced by growth factors (e.g. TGF- $\beta 1$, BMP-4), that is to avoid a loss of SMC-related markers, this stimulation needs to be followed by pulsatile strain (Wang et al., 2010). However, a different study has been successful in obtaining differentiation only by combining TGF- $\beta 1$ and uniaxial strain, as these factors showed a positive synergistic effect (Kurpinski et al., 2009).

Based on the above studies, we can conclude that two methods can be used to ensure long-term (or stable) SMC differentiation sequential stimulation (first by chemical then mechanical means) or synergistic stimulation (simultaneous chemical and mechanical stimulation).

\section{A requirement for more accurate cyclic strain models for differentiation into SMCs}

As a general rule, the duration of mechanical stimulation that is required to achieve differentiation into SMCs is longer than that for differentiation into endothelial cells. Cyclic strain should be applied for at least 3 days in order to mediate the expression of some SMC markers, such as SMA, but even this is insufficient for the expression of mature markers, such as SMMHC (Hamilton et al., 2004). Cyclic strain has also been used to induce other types of differentiation, such as differentiation into skeletal muscle cells (Haghighipour et al., 2012), neuron-like cells (Leong et al., 2012) and osteogenic lineages. It is worth noting that cyclic strain alone can evoke considerable expression of SMC markers, as well as upregulation of the osteoinductor bone morphogenic protein 2 (BMP-2) and the early matrix protein osteopontin (OPN) (Maul et al., 2011). In recent work, the role of cyclic strain intensity on MSC differentiation was investigated. It was shown that cells that are stretched at $0.1 \mathrm{~Hz}$ express higher levels of osteoblast-specific genetic and protein markers compared with cells that are stretched at $1 \mathrm{~Hz}$, which express significantly higher levels of vascular-SMC-specific genetic and protein markers (Yao and Wong, 2015). These results also support the findings of an earlier study, in which cyclic strain of a low magnitude $(0.26 \mathrm{~Hz}, 3 \%)$ mediated the differentiation of MSCs into osteogenic cells, whereas greater cyclic strain $(0.26 \mathrm{~Hz}, 10 \%)$ favoured differentiation into SMCs (Jang et al., 2011).

Further research efforts are thus required to develop protocols that promote reliable cyclic-strain-induced differentiation of cells into SMCs that exhibit a contractile phenotype for use in vascular tissue engineering.

\section{Maintaining endothelial cells and SMCs in their differentiated state}

For the purpose of vascular tissue engineering, an ideal multilayer vessel would comprise an innermost layer of endothelial cells, a middle layer of SMCs and an outer layer comprising ECM and fibroblasts. The studies summarized above suggest that shear and cyclic stress can be used to differentiate MSCs into endothelial cells and SMCs, respectively. Questions remain, however, as to whether the differentiation that has been initiated in vitro can be maintained long term and how to avoid cellular dedifferentiation once the stimulation is terminated. One of the answers could be to maintain the tissue-engineered blood vessels (TEVs) under continuous stimulation with shear stress or cyclic strain. This can be achieved in vitro with the use of bioreactors or by grafting the vessel into a host organism in vivo, thereby exploiting the host's physiological environment to generate either shear stress by blood flow or cyclic strain by pulsatile stimulation.

In the area of bioreactors, Huang et al. have recently designed a bioreactor that can better simulate the physiological stresses acting on native arteries and that allows biaxial stretching during culture (Huang and Niklason, 2014; Huang et al., 2015). Biaxial stretching induces a greater wall thickness compared with stimulation with static or uniaxial stretch. Furthermore, this stimulation leads to the development of undulated collagen fibres and mature elastin in the ECM, which might contribute to the observed vascular compliance in the biaxial TEVs obtained with this bioreactor. These results suggest that this type of bioreactor could be used to optimize biomechanical conditioning of TEVs and, thus, could help to maintain cells in a differentiated state.

Regarding the in vivo implantation of vascular grafts to improve their patency after being engineered in vitro, interesting results have been obtained. For instance, Udelsman et al. have recently engineered a vessel by using a polymer that had been seeded with bone marrow mononuclear cells, which they then implanted into mice. After 7 months, they observed the development of a luminal endothelial cell layer, as well as a SMC-populated 'medial' layer that associated with components of ECM, including elastin and collagen type I and type III, suggesting that cells that have been biomechanically stimulated in vivo could differentiate into endothelial cells or SMCs (Udelsman et al., 2014). Zhao et al. have also shown that it is possible to maintain cell differentiation after implantation in vivo. These authors constructed a TEV by using endothelial cells and SMCs that had been differentiated from MSCs and seeded onto a decellularized ovine artery, which was subsequently interposed in the carotid arteries in an ovine host model. After 5 months, the analysis of the graft showed the existence of endothelium, smooth muscle, collagen and elastin, indicating that differentiation had been maintained over this period of time (Zhao et al., 2010).

\section{Conclusion and perspectives}

Shear stresses at physiological levels can differentiate MSCs into endothelial cells by inducing the expression of endothelial-cellspecific markers and endothelial-cell -specific functional properties. Cyclic strain, both in 2D and 3D models, can guide MSCs to differentiate into SMCs by inducing the expression of several SMCassociated markers. However, compared with shear stress-mediated endothelial cell differentiation, cyclic strain alone has only a relatively limited ability to induce SMC differentiation. It is clear that mechanical force can increase vascular differentiation in combination with biochemical factors, such as growth factors. Taken together, the studies described here suggest that the most effective device for generating high-functioning TEVs would be one that is capable of applying shear stress and cyclic strain on seeded MSC-derived endothelial cells and SMCs, in order to maintain their activity and differentiation state before use in tissue 
engineering. However, much remains to be done to progress from 2D to 3D models and from in vitro to in vivo applications in order to be able to produce a mechanical-force-mediated tissue-engineered vessel for clinical use.

\section{Acknowledgements}

We thank Professor Kira Weissman for careful reading of the review.

\section{Competing interests}

The authors declare no competing or financial interests.

\section{Funding}

This study was supported by an overseas fellowship from the China scholarship council.

\section{References}

Ahsan, T. and Nerem, R. M. (2010). Fluid shear stress promotes an endothelial-like phenotype during the early differentiation of embryonic stem cells. Tissue Eng. A 16, 3547-3553

Ando, J. and Yamamoto, K. (2009). Vascular mechanobiology: endothelial cell responses to fluid shear stress. Circ. J. Off. J. Jpn. Circ. Soc. 73, 1983-1992.

Bai, K., Huang, Y., Jia, X., Fan, Y. and Wang, W. (2010). Endothelium oriented differentiation of bone marrow mesenchymal stem cells under chemical and mechanical stimulations. J. Biomech. 43, 1176-1181.

Barradas, A. M. C., Monticone, V., Hulsman, M., Danoux, C., Fernandes, H., Tahmasebi Birgani, Z., Barrère-de Groot, F., Yuan, H., Reinders, M. Habibovic, P. et al. (2013). Molecular mechanisms of biomaterial-driven osteogenic differentiation in human mesenchymal stromal cells. Integr. Biol. 5, 920-931.

Bassaneze, V., Barauna, V. G., Lavini-Ramos, C., Kalil, J., Schettert, I. T., Miyakawa, A. A. and Krieger, J. E. (2010). Shear stress induces nitric oxidemediated vascular endothelial growth factor production in human adipose tissue mesenchymal stem cells. Stem Cells Dev. 19, 371-378.

Bruzewicz, D. A., McGuigan, A. P. and Whitesides, G. M. (2008). Fabrication of a modular tissue construct in a microfluidic chip. Lab. Chip 8, 663-671.

Cheng, M., Guan, X., Li, H., Cui, X., Zhang, X., Li, X., Jing, X., Wu, H. and Avsar, E. (2013). Shear stress regulates late EPC differentiation via mechanosensitive molecule-mediated cytoskeletal rearrangement. PLOS ONE 8, e67675.

Davies, P. F. (2009). Hemodynamic shear stress and the endothelium in cardiovascular pathophysiology. Nat. Clin. Pract. Cardiovasc. Med. 6, 16-26.

Dong, J.-d., Gu, Y.-q., Li, C.-m., Wang, C.-r., Feng, Z.-g., Qiu, R.-X., Chen, B., Li, J.-x., Zhang, S.-w., Wang, Z.-g. et al. (2009). Response of mesenchymal stem cells to shear stress in tissue-engineered vascular grafts. Acta Pharmacol. Sin. 30, 530-536.

Du, Y., Ghodousi, M., Qi, H., Haas, N., Xiao, W. and Khademhosseini, A. (2011). Sequential assembly of cell-laden hydrogel constructs to engineer vascular-like microchannels. Biotechnol. Bioeng. 108, 1693-1703.

El Omar, R., Beroud, J., Stoltz, J.-F., Menu, P., Velot, E. and Decot, V. (2014) Umbilical cord mesenchymal stem cells: the new gold standard for mesenchymal stem cell-based therapies? Tissue Eng. B Rev. 20, 523-544.

Engelmayr, G. C., Jr, Sales, V. L., Mayer, J. E., Jr and Sacks, M. S. (2006). Cyclic flexure and laminar flow synergistically accelerate mesenchymal stem cellmediated engineered tissue formation: Implications for engineered heart valve tissues. Biomaterials 27, 6083-6095

Ferreira, L. S., Gerecht, S., Shieh, H. F., Watson, N., Rupnick, M. A., Dallabrida, S. M., Vunjak-Novakovic, G. and Langer, R. (2007). Vascular progenitor cells isolated from human embryonic stem cells give rise to endothelial and smooth muscle like cells and form vascular networks in vivo. Circ. Res. 101, 286-294.

Fischer, L. J., Mcllhenny, S., Tulenko, T., Golesorkhi, N., Zhang, P., Larson, R., Lombardi, J., Shapiro, I. and DiMuzio, P. J. (2009). Endothelial differentiation of adipose-derived stem cells: effects of endothelial cell growth supplement and shear force. J. Surg. Res. 152, 157-166.

Folkman, J. and Haudenschild, C. (1980). Angiogenesis in vitro. Nature 288 551-556.

Ghazanfari, S., Tafazzoli-Shadpour, M. and Shokrgozar, M. A. (2009). Effects of cyclic stretch on proliferation of mesenchymal stem cells and their differentiation to smooth muscle cells. Biochem. Biophys. Res. Commun. 388, 601-605.

Giddens, D. P., Zarins, C. K. and Glagov, S. (1993). The role of fluid mechanics in the localization and detection of atherosclerosis. J. Biomech. Eng. 115, 588-594.

Gong, Z. and Niklason, L.E. (2008). Small-diameter human vessel wall engineered from bone marrow-derived mesenchymal stem cells (hMSCs). FASEB J. 22, 1635-1648

Haghighipour, N., Heidarian, S., Shokrgozar, M. A. and Amirizadeh, N. (2012). Differential effects of cyclic uniaxial stretch on human mesenchymal stem cell into skeletal muscle cell. Cell Biol. Int. 36, 669-675.
Hamilton, D. W., Maul, T. M. and Vorp, D. A. (2004). Characterization of the response of bone marrow-derived progenitor cells to cyclic strain: implications for vascular tissue-engineering applications. Tissue Eng. 10, 361-369.

Hoey, D. A., Tormey, S., Ramcharan, S., O'Brien, F. J. and Jacobs, C. R. (2012). Primary cilia-mediated mechanotransduction in human mesenchymal stem cells. Stem Cells 30, 2561-2570.

Hoffman, B. D., Grashoff, C. and Schwartz, M. A. (2011). Dynamic molecular processes mediate cellular mechanotransduction. Nature 475, 316-323.

Huang, N. F. and Li, S. (2008). Mesenchymal stem cells for vascular regeneration Regen. Med. 3, 877-892.

Huang, A. H. and Niklason, L. E. (2014). Engineering of arteries in vitro. Cell. Mol. Life Sci. 71, 2103-2118.

Huang, Y., Jia, X., Bai, K., Gong, X. and Fan, Y. (2010). Effect of fluid shear stress on cardiomyogenic differentiation of rat bone marrow mesenchymal stem cells. Arch. Med. Res. 41, 497-505.

Huang, F., Fang, Z.-f., Hu, X.-q., Tang, L., Zhou, S.-h. and Huang, J.-p. (2013) Overexpression of miR-126 promotes the differentiation of mesenchymal stem cells toward endothelial cells via activation of PI3K/Akt and MAPK/ERK pathways and release of paracrine factors. Biol. Chem. 394, 1223-1233.

Huang, A. H., Lee, Y.-U., Calle, E. A., Boyle, M., Starcher, B. C., Humphrey, J. D. and Niklason, L. E. (2015). Design and use of a novel bioreactor for regeneration of biaxially stretched tissue-engineered vessels. Tissue Eng. Part C Methods. [Epub ahead of print] doi:10.1089/ten.tec.2014.0287.

Jang, J.-Y., Lee, S. W., Park, S. H., Shin, J. W., Mun, C., Kim, S.-H., Kim, D. H. and Shin, J.-W. (2011). Combined effects of surface morphology and mechanical straining magnitudes on the differentiation of mesenchymal stem cells without using biochemical reagents. J. Biomed. Biotechnol. 2011, 860652.

Janmey, P. A. and McCulloch, C. A. (2007). Cell mechanics: integrating cell responses to mechanical stimuli. Annu. Rev. Biomed. Eng. 9, 1-34.

Kaneko, K., Ito, M., Naoe, Y., Lacy-Hulbert, A. and Ikeda, K. (2014). Integrin $\alpha$ v in the mechanical response of osteoblast lineage cells. Biochem. Biophys. Res. Commun. 447, 352-357

Khan, O. F. and Sefton, M. V. (2010). Perfusion and characterization of an endothelial cell-seeded modular tissue engineered construct formed in a microfluidic remodeling chamber. Biomaterials 31, 8254-8261.

Khan, O. F., Chamberlain, M. D. and Sefton, M. V. (2012). Toward an in vitro vasculature: differentiation of mesenchymal stromal cells within an endothelial cell-seeded modular construct in a microfluidic flow chamber. Tissue Eng. A 18 744-756.

Kim, D. H., Heo, S.-J., Kim, S.-H., Shin, J. W., Park, S. H. and Shin, J.-W. (2011) Shear stress magnitude is critical in regulating the differentiation of mesenchymal stem cells even with endothelial growth medium. Biotechnol. Lett. 33, 2351-2359.

Kobayashi, N., Yasu, T., Ueba, H., Sata, M., Hashimoto, S., Kuroki, M., Saito, M. and Kawakami, M. (2004). Mechanical stress promotes the expression of smooth muscle-like properties in marrow stromal cells. Exp. Hematol. 32, 1238-1245.

Koike, N., Fukumura, D., Gralla, O., Au, P., Schechner, J. S. and Jain, R. K (2004). Tissue engineering: creation of long-lasting blood vessels. Nature $\mathbf{4 2 8}$ 138-139.

Kreke, M. R., Huckle, W. R. and Goldstein, A. S. (2005). Fluid flow stimulates expression of osteopontin and bone sialoprotein by bone marrow stromal cells in temporally dependent manner. Bone 36, 1047-1055.

Kreke, M. R., Sharp, L. A., Woo Lee, Y. and Goldstein, A. S. (2008). Effect of intermittent shear stress on mechanotransductive signaling and osteoblastic differentiation of bone marrow stromal cells. Tissue Eng. A 14, 529-537.

Kurpinski, K., Chu, J., Wang, D. and Li, S. (2009). Proteomic profiling of mesenchymal stem cell responses to mechanical strain and TGF-beta1. Cell. Mol. Bioeng. 2, 606-614.

Kurpinski, K., Park, J., Thakar, R. G. and Li, S. (2006). Regulation of vascula smooth muscle cells and mesenchymal stem cells by mechanical strain. Mol. Cell. Biomech. 3, 21-34

le Noble, F., Moyon, D., Pardanaud, L., Yuan, L., Djonov, V., Matthijsen, R., Bréant, C., Fleury, V. and Eichmann, A. (2004). Flow regulates arterial-venous differentiation in the chick embryo yolk sac. Development 131, 361-375.

Lee, W.-C.C., Maul, T. M., Vorp, D. A., Rubin, J. P. and Marra, K. G. (2007). Effects of uniaxial cyclic strain on adipose-derived stem cell morphology, proliferation, and differentiation. Biomech. Model. Mechanobiol. 6, 265-273.

Leong, W. S., Wu, S. C., Pal, M., Tay, C. Y., Yu, H., Li, H. and Tan, L. P. (2012). Cyclic tensile loading regulates human mesenchymal stem cell differentiation into neuron-like phenotype. J. Tissue Eng. Regen. Med. 6 Suppl. 3, s68-s79.

L'heureux, N., Pâquet, S., Labbé, R., Germain, L. and Auger, F. A. (1998). A completely biological tissue-engineered human blood vessel. FASEB J. 12 , 47-56.

L'Heureux, N., Dusserre, N., Konig, G., Victor, B., Keire, P., Wight, T. N., Chronos, N. A. F., Kyles, A. E., Gregory, C. R., Hoyt, G. et al. (2006). Human tissue-engineered blood vessels for adult arterial revascularization. Nat. Med. 12 361-365

L'Heureux, N., Dusserre, N., Marini, A., Garrido, S., de la Fuente, L. and McAllister, T. (2007). Technology Insight: the evolution of tissue-engineered vascular grafts-from research to clinical practice. Nat. Clin. Pract. Cardiovasc. Med. 4, 389-395. 
Lim, J. Y., Loiselle, A. E., Lee, J. S., Zhang, Y., Salvi, J. D. and Donahue, H. J. (2011). Optimizing the osteogenic potential of adult stem cells for skeletal regeneration. J. Orthop. Res. 29, 1627-1633.

Liu, Y.-S. and Lee, O. K. (2014). In search of the pivot point of mechanotransduction: mechanosensing of stem cells. Cell Transplant. 23, 1-11.

Maul, T. M., Chew, D. W., Nieponice, A., and Vorp, D. A. (2011). Mechanical stimuli differentially control stem cell behavior: morphology, proliferation, and differentiation. Biomech. Model. Mechanobiol. 10, 939-953.

McBride, S. H., Falls, T. and Knothe Tate, M. L. (2008). Modulation of stem cell shape and fate $B$ : mechanical modulation of cell shape and gene expression. Tissue Eng. A 14, 1573-1580.

Mironov, V., Kasyanov, V. and Markwald, R. R. (2011). Organ printing: from bioprinter to organ biofabrication line. Curr. Opin. Biotechnol. 22, 667-673.

Nieponice, A., Maul, T. M., Cumer, J. M., Soletti, L. and Vorp, D. A. (2007) Mechanical stimulation induces morphological and phenotypic changes in bone marrow-derived progenitor cells within a three-dimensional fibrin matrix. J. Biomed. Mater. Res. A 81A, 523-530

O'Cearbhaill, E. D., Punchard, M. A., Murphy, M., Barry, F. P., McHugh, P. E. and Barron, V. (2008). Response of mesenchymal stem cells to the biomechanical environment of the endothelium on a flexible tubular silicone substrate. Biomaterials 29, 1610-1619.

O'Cearbhaill, E. D., Murphy, M., Barry, F., McHugh, P. E. and Barron, V. (2010). Behavior of human mesenchymal stem cells in fibrin-based vascular tissue engineering constructs. Ann. Biomed. Eng. 38, 649-657.

Oswald, J., Boxberger, S., Jørgensen, B., Feldmann, S., Ehninger, G., Bornhäuser, M. and Werner, C. (2004). Mesenchymal stem cells can be differentiated into endothelial cells in vitro. Stem Cells 22, 377-384.

Owens, G. K. (1995). Regulation of differentiation of vascular smooth muscle cells Physiol. Rev. 75, 487-517.

Park, J. S., Chu, J. S. F., Cheng, C., Chen, F., Chen, D. and Li, S. (2004) Differential effects of equiaxial and uniaxial strain on mesenchymal stem cells. Biotechnol. Bioeng. 88, 359-368.

Park, J. S., Huang, N. F., Kurpinski, K. T., Patel, S., Hsu, S. and Li, S. (2007) Mechanobiology of mesenchymal stem cells and their use in cardiovascular repair. Front. Biosci. 12, 5098-5116.

Paszkowiak, J. J. and Dardik, A. (2003). Arterial wall shear stress: observations from the bench to the bedside. Vasc. Endovascular Surg. 37, 47-57.

Praetorius, H. A. and Spring, K. R. (2005). A physiological view of the primary cilium. Annu. Rev. Physiol. 67, 515-529.

Riha, G. M., Wang, X., Wang, H., Chai, H., Mu, H., Lin, P. H., Lumsden, A. B., Yao, Q. and Chen, C. (2007). Cyclic strain induces vascular smooth muscle cell differentiation from murine embryonic mesenchymal progenitor cells. Surgery 141, 394-402.

Satir, P., Pedersen, L. B. and Christensen, S. T. (2010). The primary cilium at a glance. J. Cell Sci. 123, 499-503.

Schwartz, M. A. and Assoian, R. K. (2001). Integrins and cell proliferation: regulation of cyclin-dependent kinases via cytoplasmic signaling pathways. J. Cell Sci. 114, 2553-2560.

Seifu, D. G., Purnama, A., Mequanint, K. and Mantovani, D. (2013). Smalldiameter vascular tissue engineering. Nat. Rev. Cardiol. 10, 410-421.

Shah, N., Morsi, Y. and Manasseh, R. (2014). From mechanical stimulation to biological pathways in the regulation of stem cell fate. Cell Biochem. Funct. $\mathbf{3 2}$ 309-325.

Shin'oka, T., Imai, Y. and Ikada, Y. (2001). Transplantation of a tissue-engineered pulmonary artery. N. Engl. J. Med. 344, 532-533.

Shojaei, S., Tafazzoli-Shahdpour, M., Shokrgozar, M. A. and Haghighipour, N. (2013). Effects of mechanical and chemical stimuli on differentiation of human adipose-derived stem cells into endothelial cells. Int. J. Artif. Organs 36, 663-673.

Shyy, J. Y.-J. and Chien, S. (2002). Role of integrins in endothelial mechanosensing of shear stress. Circ. Res. 91, 769-775.

Smith, Q. and Gerecht, S. (2014). Going with the flow: microfluidic platforms in vascular tissue engineering. Curr. Opin. Chem. Eng. 3, 42-50.
Stolberg, S. and McCloskey, K. E. (2009). Can shear stress direct stem cell fate? Biotechnol. Prog. 25, 10-19.

Udelsman, B. V., Khosravi, R., Miller, K. S., Dean, E. W., Bersi, M. R., Rocco, K., Yi, T., Humphrey, J. D. and Breuer, C. K. (2014). Characterization of evolving biomechanical properties of tissue engineered vascular grafts in the arterial circulation. J. Biomech. 47, 2070-2079.

Vlahakis, N. E., Young, B. A., Atakilit, A., Hawkridge, A. E., Issaka, R. B., Boudreau, N. and Sheppard, D. (2007). Integrin alpha9beta1 directly binds to vascular endothelial growth factor (VEGF)-A and contributes to VEGF-A-induced angiogenesis. J. Biol. Chem. 282, 15187-15196.

Wang, H., Riha, G. M., Yan, S., Li, M., Chai, H., Yang, H., Yao, Q., and Chen, C. (2005). Shear stress induces endothelial differentiation from a murine embryonic mesenchymal progenitor cell line. Arterioscler. Thromb. Vasc. Biol. 25 1817-1823.

Wang, H., Li, M., Lin, P. H., Yao, Q. and Chen, C. (2008). Fluid shear stress regulates the expression of TGF-beta1 and its signaling molecules in mouse embryo mesenchymal progenitor cells. J. Surg. Res. 150, 266-270.

Wang, C., Cen, L., Yin, S., Liu, Q., Liu, W., Cao, Y. and Cui, L. (2010). A small diameter elastic blood vessel wall prepared under pulsatile conditions from polyglycolic acid mesh and smooth muscle cells differentiated from adiposederived stem cells. Biomaterials 31, 621-630.

Weinberg, P. D. and Ross Ethier, C. (2007). Twenty-fold difference in hemodynamic wall shear stress between murine and human aortas. J. Biomech. 40, 1594-1598.

Wu, Z., Wong, K., Glogauer, M., Ellen, R. P. and McCulloch, C. A. G. (1999) Regulation of stretch-activated intracellular calcium transients by actin filaments. Biochem. Biophys. Res. Commun. 261, 419-425.

Wu, C.-C., Chao, Y.-C., Chen, C.-N., Chien, S., Chen, Y.-C., Chien, C.-C., Chiu, J.-J. and Linju Yen, B. (2008). Synergism of biochemical and mechanical stimuli in the differentiation of human placenta-derived multipotent cells into endothelial cells. J. Biomech. 41, 813-821.

Yamamoto, K., Sokabe, T., Watabe, T., Miyazono, K., Yamashita, J. K., Obi, S. Ohura, N., Matsushita, A., Kamiya, A. and Ando, J. (2005). Fluid shear stress induces differentiation of Flk-1-positive embryonic stem cells into vascula endothelial cells in vitro. Am. J. Physiol. Heart Circ. Physiol. 288, H1915-H1924.

Yamawaki, H. Pan, S. Lee, R. T. and Berk, B. C. (2005). Fluid shear stress inhibits vascular inflammation by decreasing thioredoxin-interacting protein in endothelial cells. J. Clin. Invest. 115, 733-738.

Yao, R. and Wong, J. Y. (2015). The effects of mechanical stimulation on controlling and maintaining marrow stromal cell differentiation into vascular smooth muscle cells. J. Biomech. Eng. 137, 020907.

Yeatts, A. B., Geibel, E. M., Fears, F. F. and Fisher, J. P. (2012). Human mesenchymal stem cell position within scaffolds influences cell fate during dynamic culture. Biotechnol. Bioeng. 109, 2381-2391.

Yuan, L., Sakamoto, N., Song, G. and Sato, M. (2013). High-level shear stress stimulates endothelial differentiation and VEGF secretion by human mesenchymal stem cells. Cell. Mol. Bioeng. 6, 220-229.

Zhang, P., Baxter, J., Vinod, K., Tulenko, T. N. and Di Muzio, P. J. (2009) Endothelial differentiation of amniotic fluid-derived stem cells: synergism of biochemical and shear force stimuli. Stem Cells Dev. 18, 1299-1308.

Zhang, P., Moudgill, N., Hager, E., Tarola, N., DiMatteo, C., Mcllhenny, S., Tulenko, T. and DiMuzio, P. J. (2011). Endothelial differentiation of adiposederived stem cells from elderly patients with cardiovascular disease. Stem Cells Dev. 20, 977-988.

Zhao, Y., Zhang, S., Zhou, J., Wang, J., Zhen, M., Liu, Y., Chen, J. and Qi, Z (2010). The development of a tissue-engineered artery using decellularized scaffold and autologous ovine mesenchymal stem cells. Biomaterials 31 296-307.

Zheng, W., Xie, Y., Zhang, W., Wang, D., Ma, W., Wang, Z. and Jiang, X. (2012). Fluid flow stress induced contraction and re-spread of mesenchymal stem cells: a microfluidic study. Integr. Biol. 4, 1102-1111.

Zhou, J. and Niklason, L. E. (2012). Microfluidic artificial "vessels" for dynamic mechanical stimulation of mesenchymal stem cells. Integr. Biol. 4, 1487. 